Article

\title{
The Influence of Disc Surface Topography after Vapor Blasting on Wear of Sliding Pairs under Dry Sliding Conditions
}

\author{
Andrzej Dzierwa ${ }^{1, *}$, Pawel Pawlus ${ }^{1}$ and Wieslaw Zelasko ${ }^{2}$ \\ 1 Faculty of Mechanical Engineering and Aeronautics, Rzeszow University of Technology, Powstancow \\ Warszawy 8 Street, 35-959 Rzeszow, Poland; ppawlus@prz.edu.pl \\ 2 Faculty of Mechanics and Technology, Rzeszow University of Technology, Kwiatkowskiego Street, \\ 37-450 Stalowa Wola, Poland; w.zelasko@prz.edu.pl \\ * Correspondence: adzierwa@prz.edu.pl; Tel.: +48-17-743-2546
}

Received: 11 December 2019; Accepted: 21 January 2020; Published: 23 January 2020

\begin{abstract}
Wear tests were performed using a ball-on-disc tribological tester. In this study, $42 \mathrm{CrMo} 4$ steel disc of hardness $40 \mathrm{HRC}$ co-acted with 100Cr6 steel ball with hardness of $60 \mathrm{HRC}$. Disc surfaces were created using vapor blasting to obtain values of the Sq parameter close to $5 \mu \mathrm{m}$. However, other disc surface topography parameters varied. Dry friction tests were carried out. Wear levels of discs and balls were measured using a white light interferometer Talysurf CCI Lite. It was found that the surface topography had a significant impact on tribological properties under dry sliding conditions. The research also allowed to identify significant dependencies between surface topography parameters and wear.
\end{abstract}

Keywords: wear; friction; surface topography

\section{Introduction}

The surface topography is one of the most important factors determining the quality of a surface layer. It defines a set of all overlapping irregularities of surface resulting from the machining processes and wear of materials. The use of all parameters [1] to assess the surface topography in terms of its functional characteristics is not entirely possible. A large simplification, however, is the attempt to assess the surface topography using only one parameter, that often happens in the industrial practice.

Despite the fact that a significant number of works have been made in the field of relationships between surface texture and tribological parameters, dependencies between surface topography parameters and friction and wear are not yet clearly defined [2-6].

The results obtained by the authors of papers $[7,8]$ showed that the roughness amplitude had a significant impact on the transition between various friction regimes. The results of the ball-on-disc studies presented in papers $[9,10]$ indicate the existence of a correlation between surface topography parameters (in particular Rsk and Rku) and the friction force. The Rsk parameter (skewness of the assessed profile) is the third order moment. It characterizes symmetry of the height distribution. The Rku parameter, which is fourth order moment described sharpness of the ordinate distribution. The Ssk and Sku parameters are three-dimensional extensions of the Rsk and Rku parameters, respectively. The coefficient of friction under dry conditions was lower for higher surface height. However, wear was not investigated in these works. The dependencies between the Ssk and Sku parameters and volumetric wear are presented in [11]. Larger values of the Sku parameter and smaller, negative Ssk parameters led to the reduction of wear volume of smooth steel discs. Grabon et al. [12] also found that the wear of a cylinder liner with a negative skewness was smaller compared to a 
cylinder liner with a skewness close to 0 with the same value of the Sq parameter (root mean square deviation of the surface height) for both liners.

The influence of the surface topography on the frictional resistance in conditions of fretting wear was studied by, among others, authors of papers [13,14]. They received a lower coefficient of friction for rougher disc. Different results were obtained by the authors of reference [15], in which higher values of surface height corresponded to higher values of the friction coefficient. The results of the study of the effect of surface texture on fretting in dry friction conditions are presented in reference [16]. The tests revealed that the initial surface roughness had a significant effect on the obtained results. Especially tribological effects of spatial properties of the surface texture were significant.

Nyman et al. [17] pointed out that by characterizing the surface texture and calculating the several surface topography parameters like the average summit curvature Ssc and rms slope Sdq is possible to predict the remaining lifetime of a sintered friction material in a wet clutch. The authors of [18] showed that the average value of the coefficient of friction in lubricated sliding strongly depended on the mean arithmetical slope of the profile. The authors of paper [19] indicated that the standard deviation of surface height Sq and the summit density Sds were important from the point of view of the frictional resistance. The authors of [20] found a linear relationship between the roughness height of cylinder surface and friction of the cylinder liner-piston ring assembly.

One can see from a literature review that the effect of the surface topography of contacting elements on tribological performances of sliding pairs is uncertain. The aim of this study is to investigate the effect of the disc surface texture after vapor blasting on tribological properties of a disc-ball assembly under dry friction conditions

\section{Materials and Methods}

Tribological tests were carried out using the tribological tester T-11 made by Institute for Sustainable Technologies-National Research Institute in Radom (Poland) in a ball-on-disc configuration (Figure 1). The tribological system contained a stationary ball made of 100Cr6 steel with a hardness of $62 \pm 2 \mathrm{HRC}$ and a rotating steel disc of $40 \pm 2 \mathrm{HRC}$ hardness. Disc material was $42 \mathrm{CrMo} 4$ steel. Discs and balls diameters were $25 \mathrm{~mm}$ and $6.35 \mathrm{~mm}$, respectively. Vapor blasting using the KIS-900 equipment was the finishing treatment of all discs. Its fundamental technical parameters are as follows:

- Working pressure: $0.3-0.7 \mathrm{MPa}$;

- Nozzle diameter: $5 \mathrm{~mm}$;

- Abrasive granulation: $0.2-1.0 \mathrm{~mm}$.

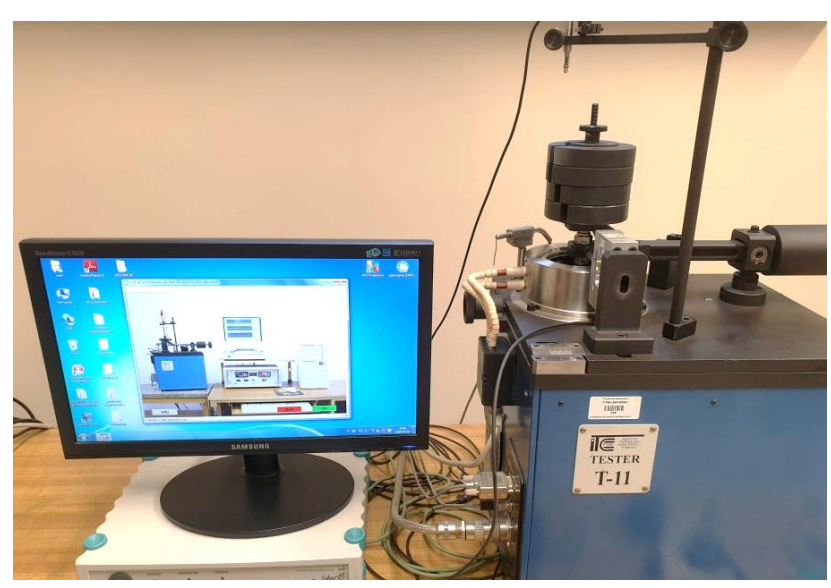

(a)

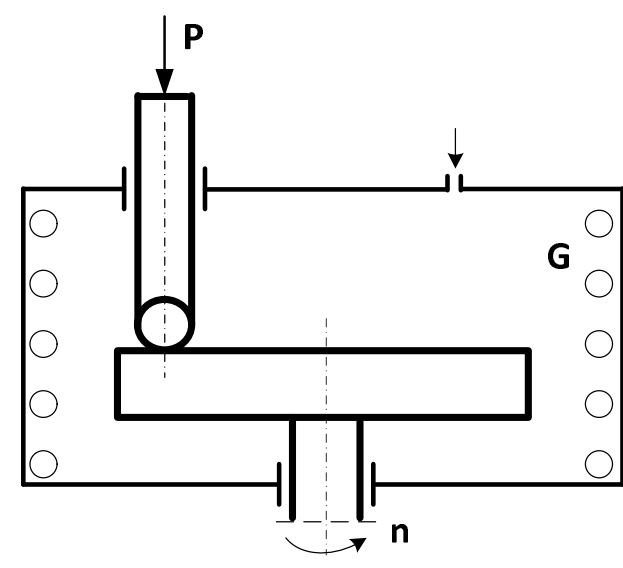

(b)

Figure 1. Photo of tribological tester T-11 (a) and scheme of frictional pair; P-load, G-heater, n-rotational speed (b). 
During vapor blasting the pressure of the feeding system was set to $0.6 \mathrm{MPa}$, and the initial flux angle was $60^{\circ}$. Aloxite 95A-60-J was an abrasive material. Its chemical composition included $95 \%$ of $\mathrm{Al}_{2} \mathrm{O}_{3} ; 2.5 \%$ of $\mathrm{TiO}_{2} ; 1.1 \%$ of $\mathrm{SiO}_{2} ; 0.3 \%$ of $\mathrm{Fe}_{2} \mathrm{O}_{3}$, and $1.1 \%$ of $\mathrm{CaO}$. Aloxite $95 \mathrm{~A}$ diameter was $0.3 \mathrm{~mm}$. Duration of vapor blasting for each sample was $4 \mathrm{~min}$. This treatment was performed in such a way to obtain a value of the Sq parameter (root mean square height of the surface) close to $5 \mu \mathrm{m}$, while other surface topography parameters varied. Different values of other surface topography parameters were obtained by slight changes of flux angle (between $55^{\circ}$ and $65^{\circ}$ ). Tribological tests were carried out in dry friction conditions at an ambient temperature of $20-22{ }^{\circ} \mathrm{C}$. The sliding speeds were: $0.16 ; 0.32 ; 0.48$, and $0.64 \mathrm{~m} / \mathrm{s}$, the sliding distance- $282.6 \mathrm{~m}$, and the normal load-9.81 N. During tribological tests, wear products were removed from the test chamber using compressed air. The number of test repetitions was three. The friction force was recorded during each test, while after its completion the amount of wear was determined using a white light interferometer Talysurf CCI Lite [21]. The measuring area was $3.29 \mathrm{~mm} \times 3.29 \mathrm{~mm}$, the sampling interval in perpendicular directions was $3.3 \mu \mathrm{m}$. The measurements of the wear tracks were taken at four positions $90^{\circ}$ apart. Then, the profiles were extracted perpendicularly to the wear tracks and the wear cross-sectional areas were calculated using TalyMap Gold 6.0 software. The calculation of volumetric wear of the disc according to Equation (1) was the next step.

$$
\mathrm{VD}=\pi \mathrm{ds}
$$

where: $\mathrm{d}$-diameter of the wear track [mm], s-cross-sectional area of the wear track $\left[\mathrm{mm}^{2}\right]$.

$\mathrm{Sq}$ is the standard deviation for the amplitudes of the surface. This parameter characterizes averaged surface amplitude, its sensitivity on the measurement errors is low. The Ssk (skewness of the assessed surface topography) and Sku (kurtosis of the surface topography) are also height parameters, however, they describe the shape of the ordinate distribution. The combination of the skewness and kurtosis allow to identify steep slopes and deep valleys on the surface. The fastest-decay autocorrelation length Sal, belonging to spatial parameters, describes the character of the surface autocorrelation function. It is a shortest autocorrelation length for which the autocorrelation function decays to 0.2 value in any possible direction. The peak density Spd, which is the feature parameter, is the number of peaks on a unit sampling area. The hybrid parameter Sdq is the root-mean-square value of the surface slope within the sampling area. Both Spd and Sdq are frequently used in contact mechanics. The remaining functional parameters Spk (reduced peak height), Sk (core roughness depth), and Svk (reduced valley depth) characterize heights of three profile parts: Peak, core, and valley, respectively [1]. They are obtained on the basis of the material ratio curve (Figure 2). These parameters are important from the tribological point of view.

Table 1 presents selected surface topography parameters according to [1] of tested discs, and Figure 3 isometric views of some of them.

Table 1. Surface topography parameters of disc samples.

\begin{tabular}{cccccccccc}
\hline \multirow{2}{*}{ Parameter } & \multicolumn{8}{c}{ Designation of Tested Discs } \\
\cline { 2 - 11 } & S1 & S2 & S3 & S4 & S5 & S6 & S7 & S8 & S9 \\
\hline Sq $(\mu \mathrm{m})$ & 4.89 & 5.11 & 4.97 & 5.21 & 4.93 & 4.98 & 4.91 & 5.17 & 4.94 \\
Ssk & -0.767 & -0.654 & -0.856 & -0.324 & -0.419 & -0.328 & -0.847 & -0.182 & -0.061 \\
Sku & 8.78 & 4.72 & 6.9 & 3.97 & 4.02 & 3.34 & 6.79 & 3.36 & 3.82 \\
Sal $(\mathrm{mm})$ & 0.0245 & 0.0267 & 0.0294 & 0.0401 & 0.0321 & 0.0883 & 0.0247 & 0.0682 & 0.0332 \\
Spd $\left(1 / \mathrm{mm}^{2}\right)$ & 404 & 387 & 307 & 315 & 935 & 639 & 404 & 729 & 1181 \\
Sdq & 0.826 & 0.752 & 0.718 & 0.644 & 0.951 & 0.745 & 0.804 & 0.839 & 1.19 \\
Sk $(\mathrm{mm})$ & 6.79 & 10.5 & 6.42 & 12.1 & 10.5 & 10.4 & 6.97 & 11.3 & 11.2 \\
Spk $(\mathrm{mm})$ & 5.99 & 4.74 & 6.08 & 4.59 & 4.45 & 3.77 & 6.14 & 4.39 & 4.6 \\
Svk $(\mathrm{mm})$ & 8.34 & 7.98 & 9.52 & 6.52 & 6.82 & 5.75 & 9.69 & 5.79 & 5.59 \\
\hline
\end{tabular}


The texture aspect ratio of the disc surfaces Str, not shown in Table 1, which is the ratio of the fastest to the slowest decays of the autocorrelation function to 0.2 value, was between 0.808 and 0.919 , indicating the isotropic character of the tested surfaces. Vapor blasted disc samples were also characterized by the negative skewness Ssk and the value of the kurtosis Sku between 3.34 and 8.78.

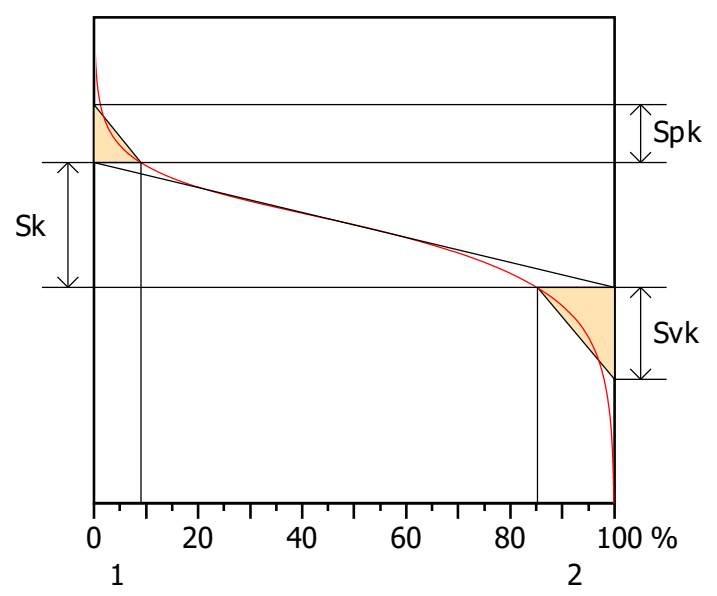

\begin{tabular}{|l|r|l|l|}
\hline Parameters & Value & Unit \\
\hline Sk & 4.88 & $\mu \mathrm{m}$ & \\
\hline Spk & 2.27 & $\mu \mathrm{m}$ & \\
\hline Svk & 3.59 & $\mu \mathrm{m}$ & \\
\hline
\end{tabular}

Figure 2. Graphical interpretation of the Spk, Svk, and Sk parameters.

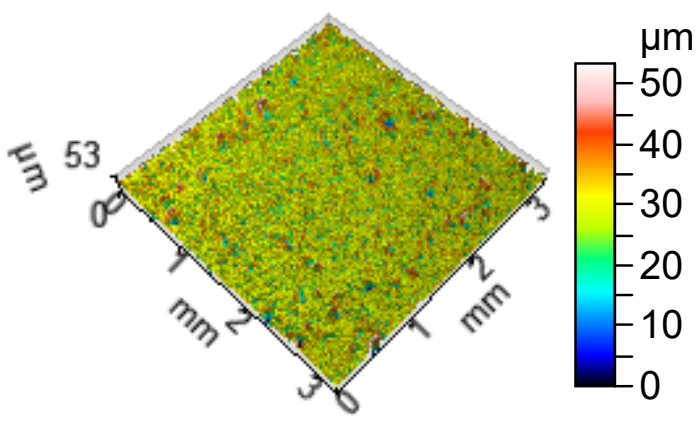

(a)

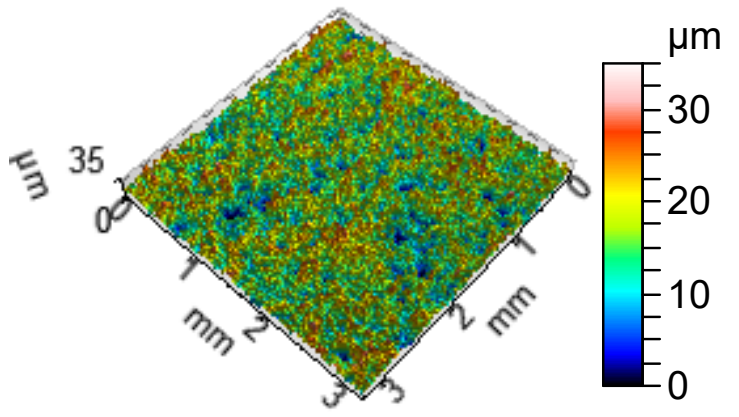

(b)

Figure 3. Isometric views of selected discs: S1 (a), S8 (b).

\section{Results and Discussion}

Figure 4 shows the results of the volumetric wear calculation of the discs (VD), while Table 2 presents the other tribological parameters. For all frictional pairs, volumetric wear of the ball (VB), the friction distance necessary to obtain a stable value of the friction force (DSS), the average value of the friction force (Fav), as well as the value of the friction force obtained for the sliding distance equal to $35 \mathrm{~m}\left(\mathrm{~F}_{35}\right)$ are presented The running-in process of all tested frictional pairs was finished for sliding distances between 65 and $109 \mathrm{~m}$. After running-in, the friction force obtained the stable value. The sliding distance of $35 \mathrm{~m}$ was chosen to analyze progress of running-in of tribological systems. Figure 5 shows the cross-sectional areas of wear tracks of selected discs. 


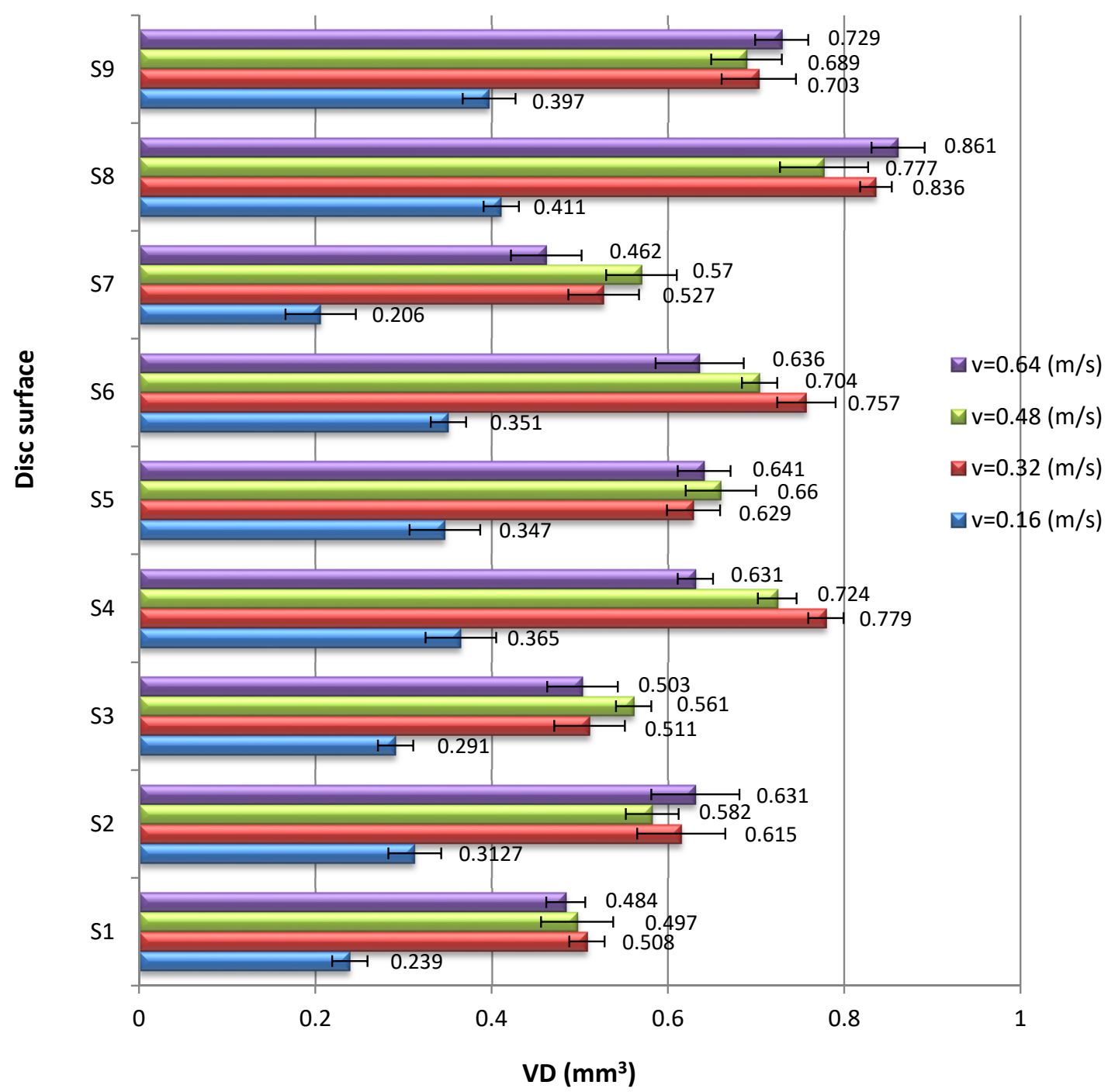

Figure 4. Volumetric wear levels of disc samples.

Table 2. Results of tribological tests.

\begin{tabular}{|c|c|c|c|c|c|c|c|c|c|c|}
\hline \multirow{2}{*}{$\mathbf{v}[\mathrm{m} / \mathrm{s}]$} & \multirow{2}{*}{ Parameter } & \multicolumn{9}{|c|}{ Disc Surface } \\
\hline & & S1 & S2 & S3 & S4 & S5 & S6 & S7 & S8 & S9 \\
\hline \multirow{4}{*}{0.16} & $\mathrm{VB}\left(\mu \mathrm{m}^{3}\right)$ & 0.0315 & 0.0346 & 0.0318 & 0.0382 & 0.0344 & 0.0375 & 0.0338 & 0.0392 & 0.0385 \\
\hline & DSS (m) & 109 & 97 & 98 & 112 & 94 & 129 & 95 & 106 & 98 \\
\hline & Fav $(\mathrm{N})$ & 8.480 & 8.293 & 8.146 & 8.695 & 8.156 & 8.176 & 8.134 & 8.208 & 8.191 \\
\hline & $\mathrm{F}_{35}(\mathrm{~N})$ & 3.576 & 3.888 & 4.074 & 4.058 & 3.906 & 3.252 & 3.66 & 4.338 & 4.121 \\
\hline \multirow{4}{*}{0.32} & $\mathrm{VB}\left(\mu \mathrm{m}^{3}\right)$ & 0.0396 & 0.0382 & 0.0411 & 0.0468 & 0.0459 & 0.0496 & 0.0477 & 0.0502 & 0.0481 \\
\hline & DSS (m) & 112 & 96 & 82 & 115 & 112 & 73 & 81 & 82 & 74 \\
\hline & Fav $(\mathrm{N})$ & 8.760 & 8.277 & 8.570 & 8.172 & 8.141 & 8.228 & 8.361 & 8.213 & 8.156 \\
\hline & $\mathrm{F}_{35}(\mathrm{~N})$ & 5.892 & 6.414 & 4.974 & 6.744 & 4.206 & 7.122 & 5.568 & 6.156 & 5.256 \\
\hline \multirow{4}{*}{0.48} & $\mathrm{VB}\left(\mu \mathrm{m}^{3}\right)$ & 0.0381 & 0.0366 & 0.0401 & 0.0439 & 0.0425 & 0.0466 & 0.0452 & 0.0489 & 0.0456 \\
\hline & DSS (m) & 98 & 92 & 92 & 88 & 91 & 89 & 95 & 78 & 82 \\
\hline & $\operatorname{Fav}(\mathrm{N})$ & 7.946 & 8.006 & 7.967 & 8.168 & 7.989 & 8.201 & 8.102 & 8.099 & 7.987 \\
\hline & $\mathrm{F}_{35}(\mathrm{~N})$ & 4.513 & 4.698 & 4.899 & 5.821 & 4.609 & 4.108 & 5.404 & 4.556 & 4.502 \\
\hline \multirow{4}{*}{0.64} & $\mathrm{VB}\left(\mu \mathrm{m}^{3}\right)$ & 0.0379 & 0.0392 & 0.0391 & 0.0408 & 0.0415 & 0.0422 & 0.0354 & 0.0469 & 0.0454 \\
\hline & DSS (m) & 96 & 88 & 80 & 92 & 96 & 92 & 98 & 74 & 78 \\
\hline & Fav (N) & 7.811 & 7.969 & 7.906 & 7.856 & 7.988 & 8.065 & 7.803 & 8.084 & 8.006 \\
\hline & $\mathrm{F}_{35}(\mathrm{~N})$ & 5.635 & 6.211 & 4.747 & 6.565 & 4.609 & 6.621 & 5.403 & 4.598 & 5.152 \\
\hline
\end{tabular}


(a)

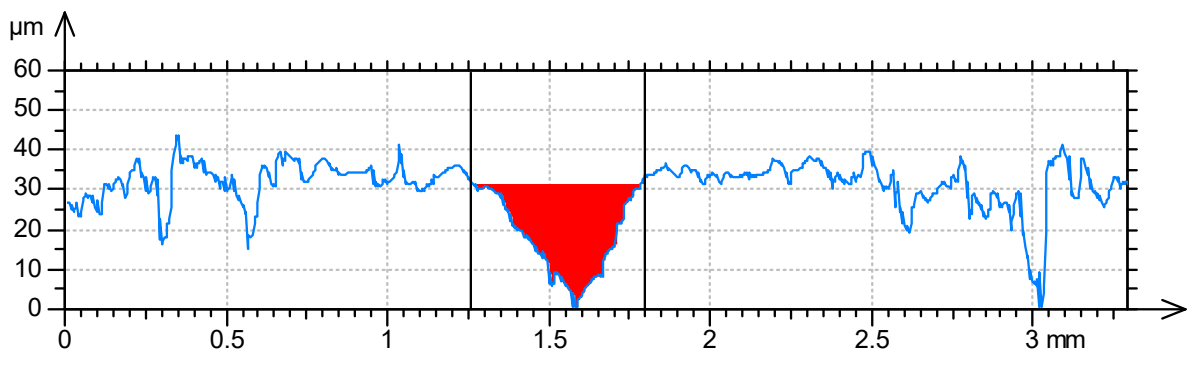

Maximum depth $\quad 32.0 \mu \mathrm{m}$ Area of the hole $\quad 7539 \mu \mathrm{m}^{2}$

(b)

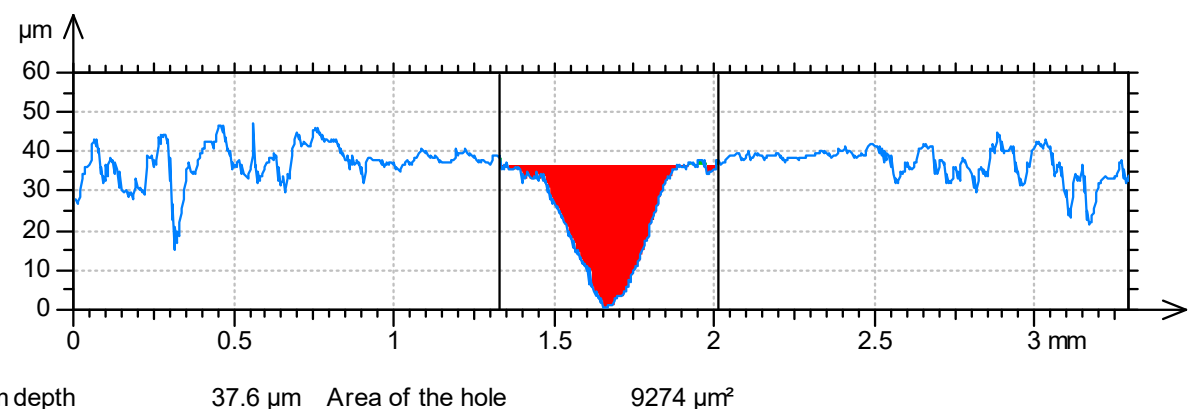

(c)

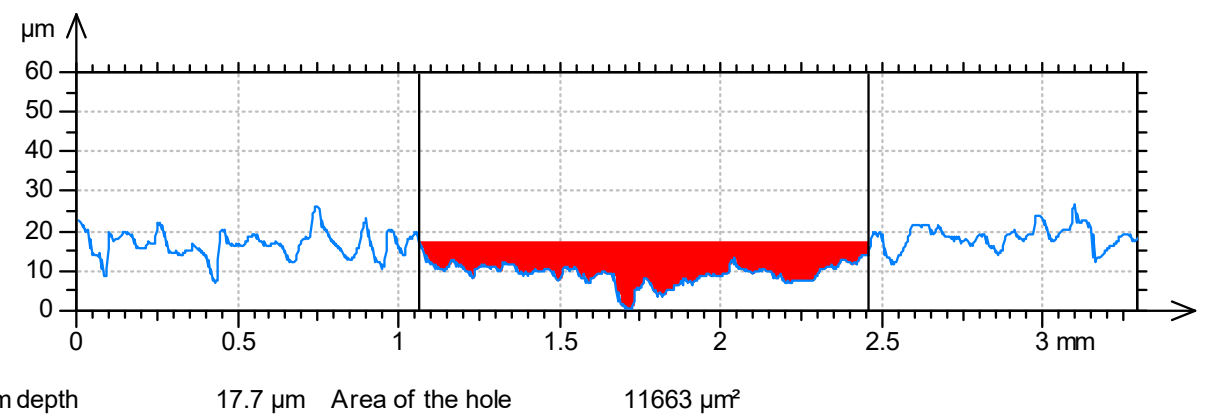

(d)

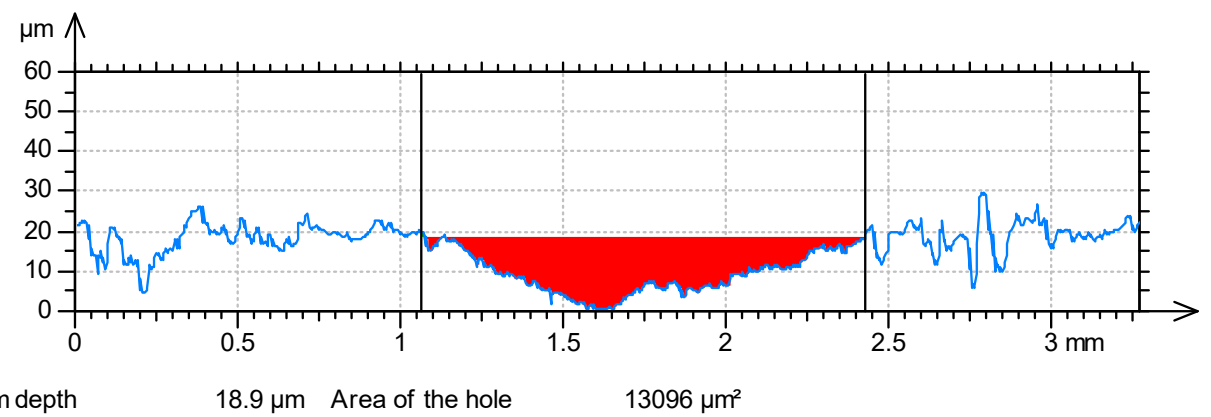

Figure 5. Cross-sectional areas of worn discs: S1 (a), S3 (b), S4 (c), S8 (d) at the sliding speed of v = 0.16 m/s.

The highest value of wear volume of the discs $\left(\mathrm{VD}=0.411 \mathrm{~mm}^{3}\right)$ at a sliding speed of $\mathrm{v}=0.16 \mathrm{~m} / \mathrm{s}$ was observed for the $\mathrm{S} 8$ sample. It corresponded to the highest value of $\mathrm{F}_{35}$ parameter. The value of the friction force obtained after a sliding distance of $35 \mathrm{~m}$ was $4.338 \mathrm{~N}$. On the other hand, the smallest value of the VD parameter for the frictional pair with S7 disc was equal to $0.206 \mathrm{~mm}^{3}$. In this case the smallest value of the DSS parameter (apart from the S5 disc) was also found. The coefficient of friction $\mu$ ranged from 0.83 (disc S7) to 0.89 (disc S4).

An increase in the sliding speed to $0.32 \mathrm{~m} / \mathrm{s}$ caused an increase in the wear volume of the discs. Similar to the sliding speed of $\mathrm{v}=0.16 \mathrm{~m} / \mathrm{s}$, the highest value of the VD parameter was obtained for the 
tribological system with the $S 8$ disc, and it was $0.836 \mathrm{~mm}^{3}$. The smallest value of volumetric wear was observed when the frictional pair contained S1 disc, and it was $0.508 \mathrm{~mm}^{3}$. This value corresponded to the longest distance necessary to obtain a stable value of the friction force $(112 \mathrm{~m})$. In this case, the highest average value of the friction force Fav was also observed. At a sliding speed of $0.32 \mathrm{~m} / \mathrm{s}$ the coefficient of friction $\mu$ achieved values from 0.83 (disc S5) to 0.89 (disc S1).

An increase in the sliding speed from 0.32 to 0.48 and $0.64 \mathrm{~m} / \mathrm{s}$ did not lead to an increase in the volumetric wear of the discs. Moreover, in most cases the VD and VB parameters were slightly reduced. The smallest VD values were calculated for S1 disc (at $v=0.48 \mathrm{~m} / \mathrm{s}$ ) and S7 disc (at v $=0.64 \mathrm{~m} / \mathrm{s}$ ) and they were 0.497 and $0.462 \mathrm{~mm}^{3}$, respectively. In both cases, the tribological systems were characterized by the highest values of the DSS parameter among other friction pairs and in both cases the value of the DSS parameter achieved $98 \mathrm{~m}$. The sliding pair with the highest wear volume for both sliding speeds contained S8 disc sample. In this case the VD parameter obtained $0.777 \mathrm{~mm}^{3}$ at $\mathrm{v}=0.48 \mathrm{~m} / \mathrm{s}$ and $0.861 \mathrm{~mm} 3$ at $\mathrm{v}=0.64 \mathrm{~m} / \mathrm{s}$.

At a sliding speed of $0.48 \mathrm{~m} / \mathrm{s}$, the friction coefficient $\mu$ ranged from 0.81 (disc S1) to 0.84 (disc S6), while at $0.64 \mathrm{~m} / \mathrm{s}$ from 0.79 (disc S7) up to 0.82 (disc S8).

The wear tracks visible on the cross-sectional areas of the discs Figure $5 c$, d don't have spherical shapes. This may indicate that during the co-acting of the elements, the initial non-conformal contact changed into a conformal [22]. The wear volume of discs was proportional to the volumetric wear of balls; the linear coefficient of correlation was between 0.69 and 0.94 .

Surface topography analysis showed the formation of a one-directional (radial) texture after wear tests. The values of the Str parameter obtained after tribological tests were in the range of $6.2 \%-11.1 \%$ being characteristic for the surfaces after abrasive wear. Figure 6 presents isometric views of $S 4$ and S6 discs after investigations and details of worn surfaces of these discs. The Str parameter of the S4 sample was $6.7 \%$, and for the $\mathrm{S} 6$ it equaled to $9.9 \%$. Figure 7 presents isometric views of balls co-acting with S4 and S6 discs after tribological tests, as well as slices of worn surfaces of those balls. The Str parameter of the ball co-acted with the S4 disc was $12.6 \%$, while of the ball contacted with the S6 disc was $10.9 \%$. The values of the Str parameter of all balls did not exceed $15 \%$, creating a surface texture similar to that of the discs. The mean square deviation of the surface height Sq was $2.51 \mu \mathrm{m}$ for the ball co-acting with the S4 disc and $2.34 \mu \mathrm{m}$ for the ball co-acting with the S6 disc (Figure 7c,d).

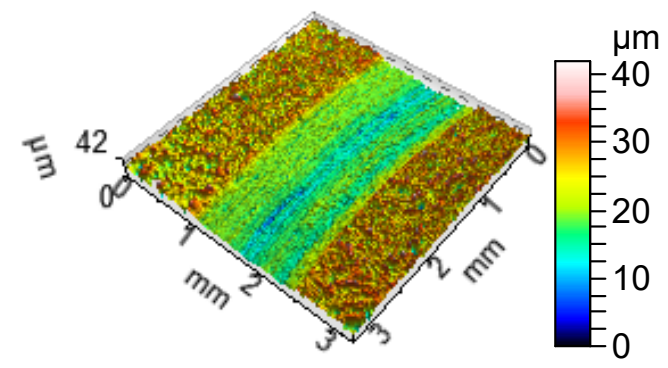

(a)

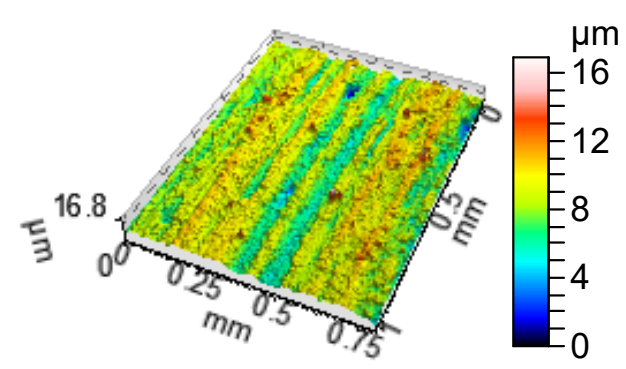

(c)

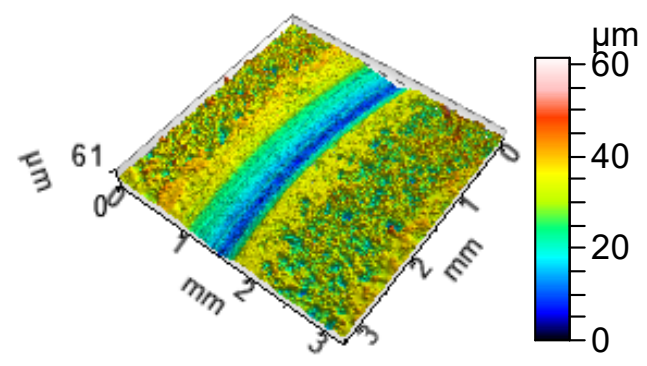

(b)

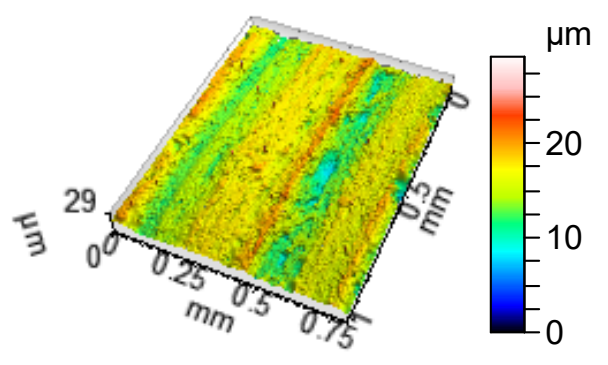

(d)

Figure 6. Isometric views of the discs S4 (a) and S6 (b) after tribological tests and details of their worn surfaces S4 (c), S6 (d). 


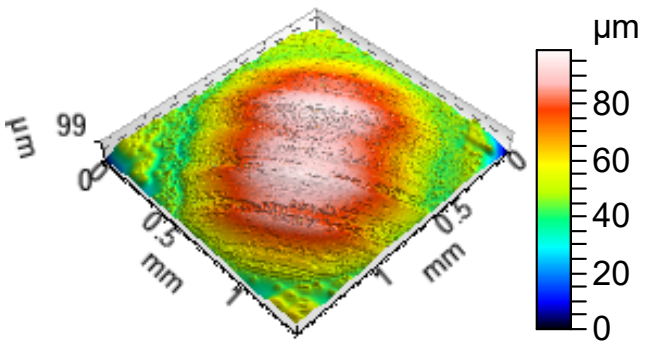

(a)

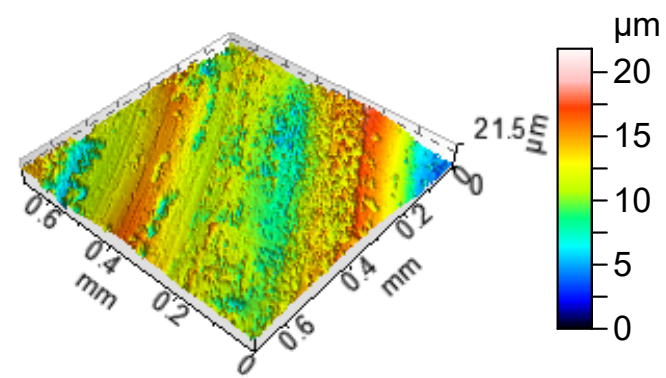

(c)

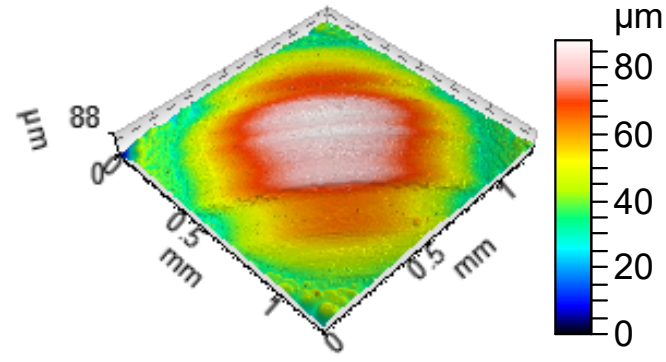

(b)

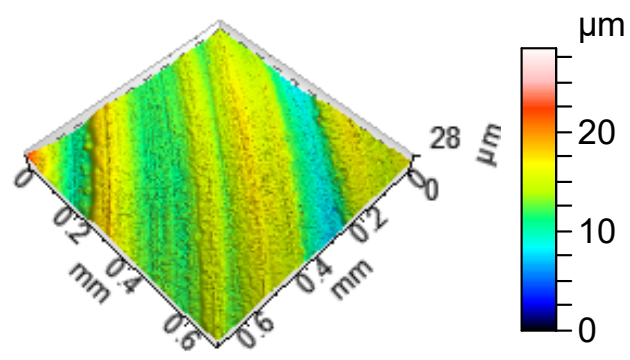

(d)

Figure 7. Isometric views of worn balls co-acting with the discs S4 (a) and S6 (b) and details of their worn surfaces co-acting with the discs S4 (c), S6 (d).

Similar to discs with a small surface height [11], abrasion was the dominant wear mechanism (Figure 8) which can be also related to high disc amplitudes. As a result of the co-action between sliding elements, truncation of the summits of the disc surfaces took place, which resulted in the creation of a new anisotropic surface texture. The craters appearing on the disc surfaces were slightly larger compared to the discs with a small surface height [11].

One can also see smooth areas with longitudinal grooves resulting from plastic deformation of disc surfaces. The increase in sliding speed did not cause significant changes of tested disc topographies. Wear of balls was significantly lower than wear of discs. This was caused by higher hardness of balls compared to that of discs. Ball surfaces were very smooth, but the presence of some abrasive particles aligned in the direction of sliding was visible. This indicated three-body mode of abrasive wear where worn material was not removed completely from the contact zone.

The coefficient of the linear correlation $\mathrm{R}$ was used to search for relationships between tribological and surface topography parameters. The value of the correlation coefficient is in the range $[-1,1]$. The higher absolute values of $\mathrm{R}$ point out the stronger linear relationship between the variables. A strong linear relationship occurring at all sliding speeds was found for the VD-Ssk (skewness) and VD-Sku (kurtosis) pairs. The Ssk parameter informs about the nature of the surface and it is sensitive on occasional deep valleys or high peaks. Zero skewness indicates a symmetrical height distribution [23]. The value of the skewness depends on whether the material is above (negative skewed) or below (positive skewed) the mean plane. The Sku parameter informs about the sharpness of the surface topography ordinate distribution. A value of Sku of 3 indicates a normal height distribution, if Sku $<3$ surface has relative few high peaks and deep valleys; whereas if $\mathrm{Sku}>3$, it has many high peaks and deep valleys [24].

The coefficient of the linear correlation $\mathrm{R}$ between volumetric wear of discs and the Ssk parameter ranged from 0.88 (for $\mathrm{v}=0.48 \mathrm{~m} / \mathrm{s}$ ) to 0.92 (for $\mathrm{v}=0.16 \mathrm{~m} / \mathrm{s}$ ), while between $\mathrm{VD}$ and $\mathrm{Sku}$, from -0.87 (for $\mathrm{v}=0.24 \mathrm{~m} / \mathrm{s}$ ) to -0.91 (for $\mathrm{v}=0.48 \mathrm{~m} / \mathrm{s}$ ).

Examples of dependencies between wear volume VD and Ssk and Sku parameters at different sliding speeds are shown in Figure 9. 
(a)

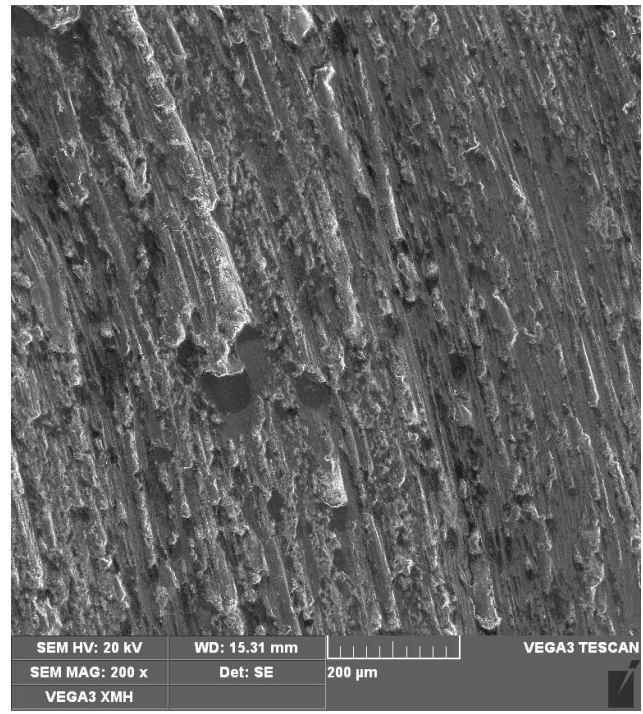

(c)

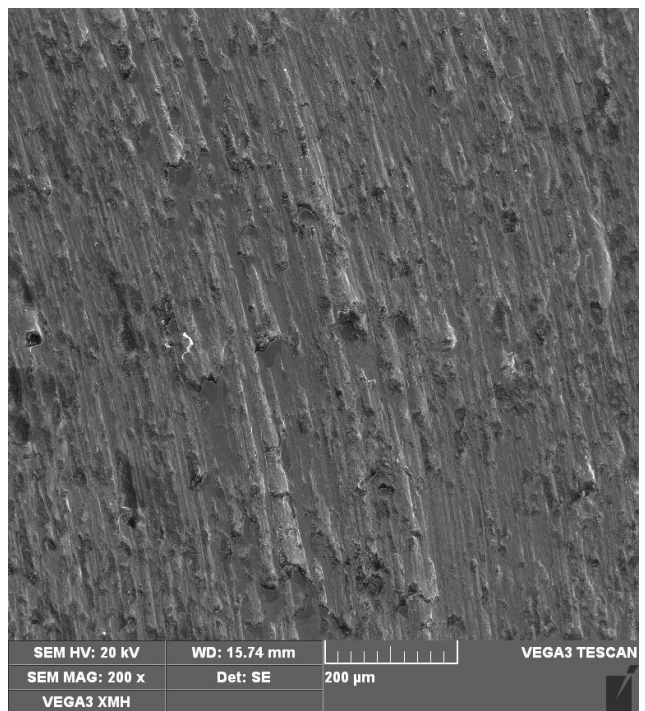

(b)

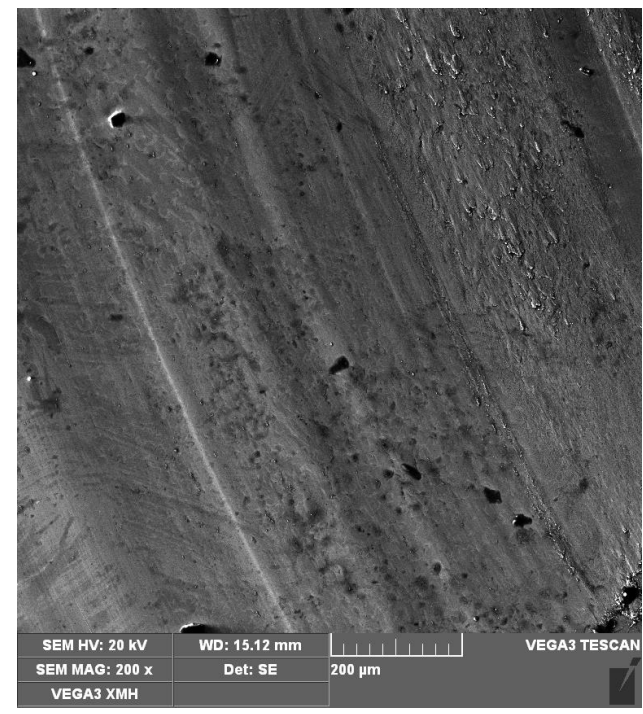

(d)

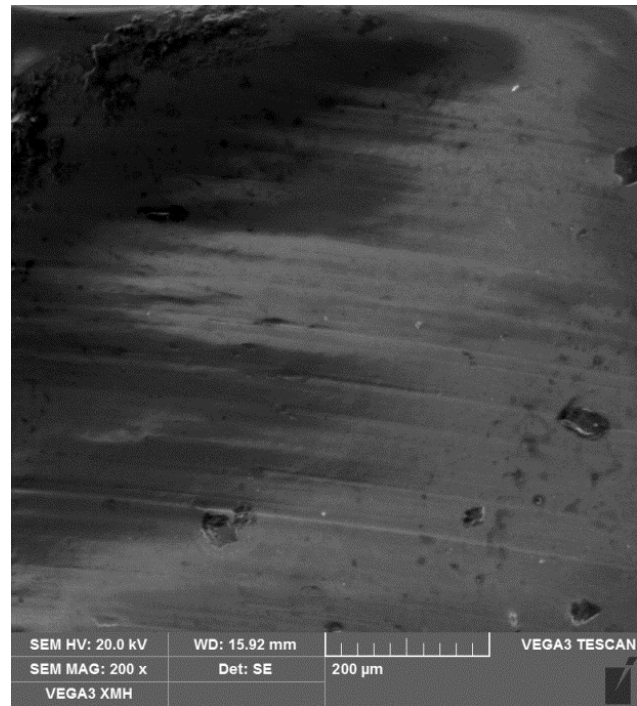

Figure 8. Worn surface of S4 disc $(\mathbf{a}, \mathbf{c})$ and co-acting ball $(\mathbf{b}, \mathbf{d})$ at the sliding speed of $\mathrm{v}=0.16 \mathrm{~m} / \mathrm{s}(\mathbf{a}, \mathbf{b})$ and $\mathrm{v}=0.64 \mathrm{~m} / \mathrm{s}(\mathbf{c}, \mathbf{d})$.

The lowest values of volumetric wear of the discs were achieved for the minimum values of the Ssk parameter and the maximum values of the Sku parameter. The Sku parameter of the discs was inversely proportional to the Ssk parameter. The coefficient of linear correlation between these parameters was -0.97. This relationship is characteristic for stratified surfaces like plateau honed cylinder texture-the negative skewness Ssk typically corresponds to the high kurtosis Sku [6]. The negative skewness can improve contact conditions by reducing the plasticity index, which in turn can cause the reduction of wear volume. The skewness Ssk is more tribologically important than the kurtosis Sku. The kurtosis is more sensitive to individual peaks or grooves presences [25]. Therefore, the dependence Ssk-VD seems to be more substantial than Sku-VD. Similar results were obtained in [11] and partially in [22] under dry friction conditions and in [12] under lubricated regime.

A strong linear dependency occurring at all sliding speeds was also found between volumetric wear of the discs and parameters characterizing the areal material ratio: Sk (core roughness depth), Spk (reduced peak height), and Svk (reduced valley depth). The Svk parameter characterizes the performance of surface in a regime of lubrication while the Spk parameter can provide information on the surface's wear resistance during the running-in (the lower value of the Spk, the greater wear 
resistance). The roughness height Sk, however, determines the roughness height after running-in and characterizes surface properties in a steady-state period [26]. Depending on the sliding speed, the values of the coefficient of linear correlation $R$ oscillated in the ranges: From 0.82 to 0.88 (for VD and $\mathrm{Sk}$ ), from -0.76 to -0.85 (for VD and Spk), and from -0.84 to -0.89 (for VD and Svk).

(a)

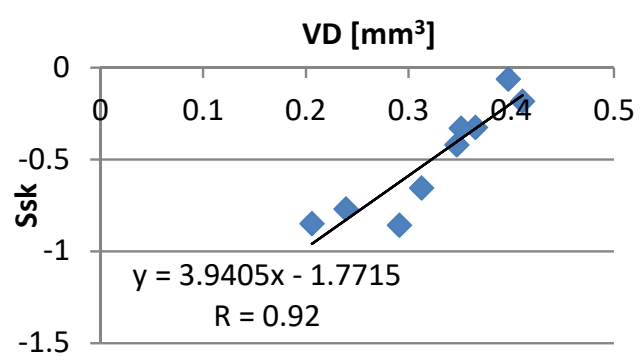

(c)

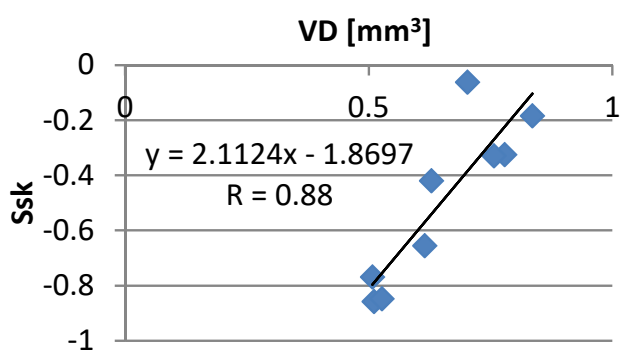

(e)

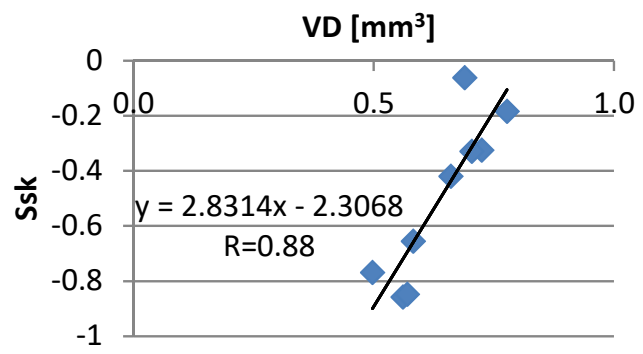

(b)

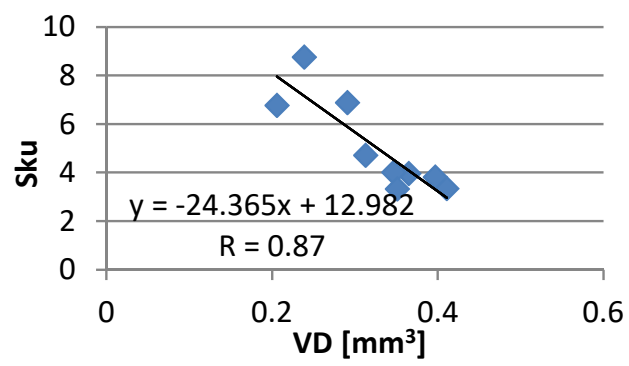

(d)

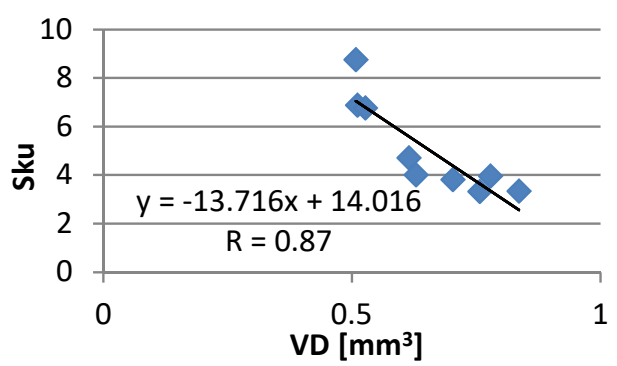

(f)

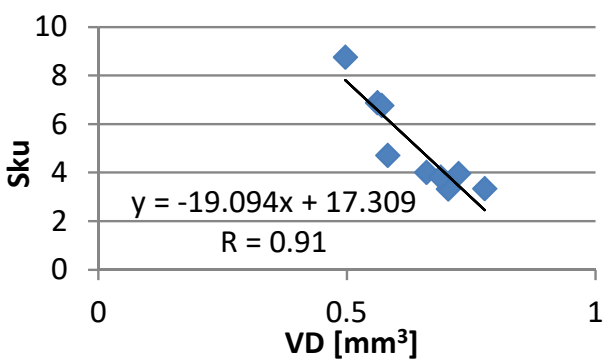

Figure 9. Dependencies between wear volume VD and Ssk $(\mathbf{a}, \mathbf{c}, \mathbf{e})$ and Sku parameters $(\mathbf{b}, \mathbf{d}, \mathbf{f})$ at the sliding speed of: $(\mathbf{a}, \mathbf{b}) \mathrm{v}=0.16 \mathrm{~m} / \mathrm{s} ;(\mathbf{c}, \mathbf{d}) \mathrm{v}=0.32 \mathrm{~m} / \mathrm{s} ;(\mathbf{e}, \mathbf{f}) \mathrm{v}=0.48 \mathrm{~m} / \mathrm{s}$.

Figure 10 shows dependencies between parameters Spk and Svk and volumetric wear VD at sliding speeds $\mathrm{v}=0.16 \mathrm{~m} / \mathrm{s}(\mathrm{a}), \mathrm{v}=0.32 \mathrm{~m} / \mathrm{s}(\mathrm{b})$, and $\mathrm{v}=0.48 \mathrm{~m} / \mathrm{s}(\mathrm{c})$. Areas marked in red indicate higher values of the VD parameter, while green color presents areas corresponding to less wear on the discs. Dependencies between the core roughness height $\mathrm{Sk}$ and the volumetric wear are shown in Figure 11.

After analysis of the obtained results, one can see that increases in the values of Spk and Svk parameters corresponded to a decrease in the wear volume of the disc (Figure 9). However, the effect of the Spk and Svk parameters on the disc volumetric wear seems to be not substantial. The effect of the Spk parameter is important only during running-in and the Svk parameter is related to starved lubrication. The proportionality between the Sk parameter and volumetric wear of disc is probably substantial. The Sk parameter governs tribological properties of machined elements in a steady-state period. One can see from the analysis of Figure 4 that wear depth of disc is a little higher than initial surface height, so the effect of the Sk parameter on disc wear can be important. For all surfaces tested the Svk parameter was higher than the Spk parameter, which is related to the negative skewness Ssk. 


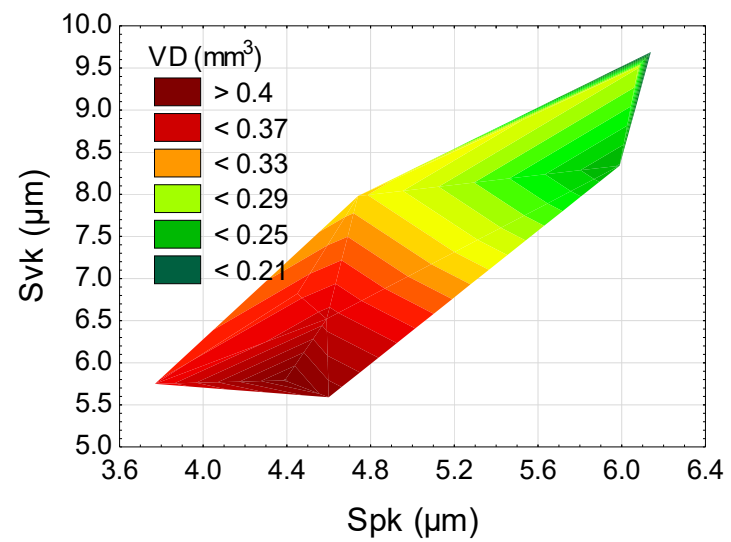

(a)

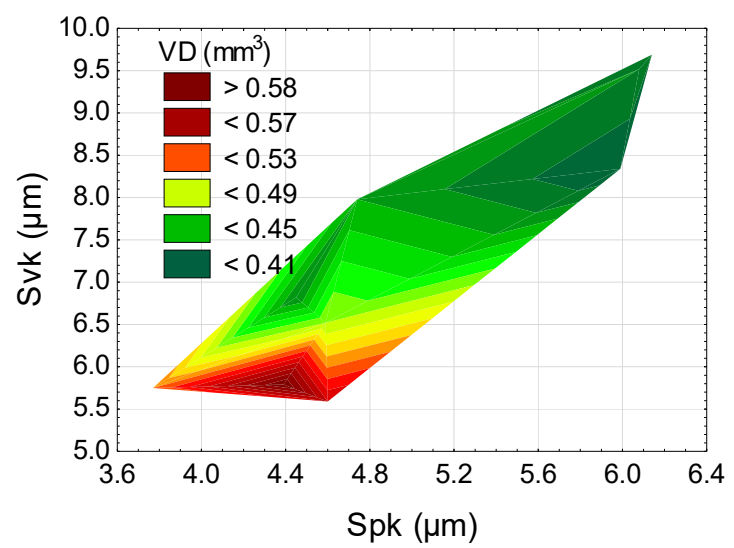

(b)

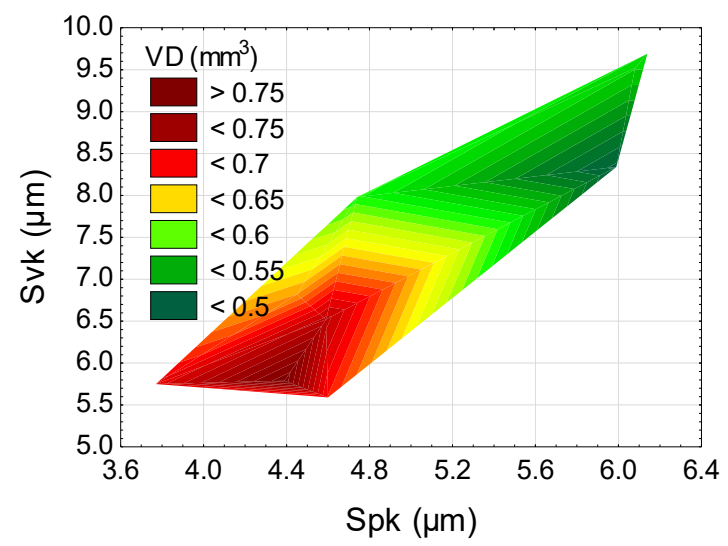

(c)

Figure 10. Dependencies between wear volume VD and Spk and Svk parameters at the sliding speed of $\mathrm{v}=0.16 \mathrm{~m} / \mathrm{s}(\mathbf{a}), \mathrm{v}=0.32 \mathrm{~m} / \mathrm{s}(\mathbf{b}), \mathrm{v}=0.48 \mathrm{~m} / \mathrm{s}(\mathbf{c})$.

(a)

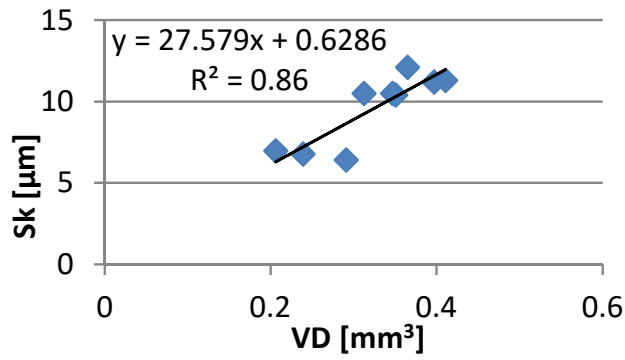

(c)

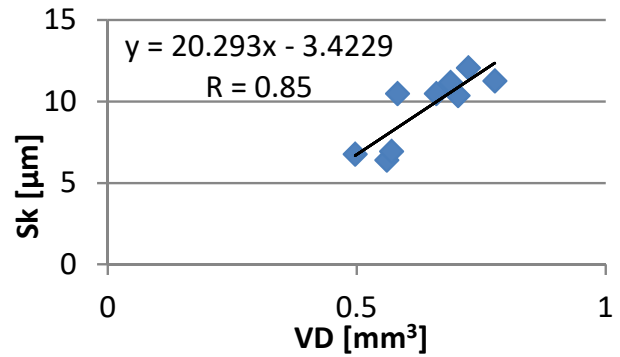

(b)

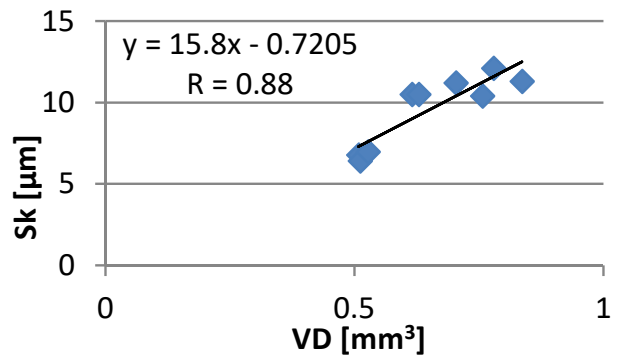

(d)

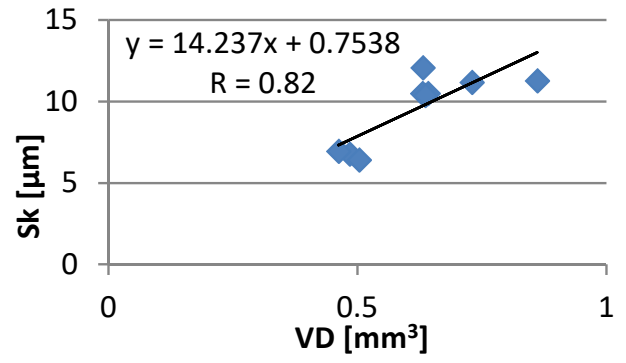

Figure 11. Dependencies between wear volume VD and Sk at the sliding speed of $(\mathbf{a}) \mathrm{v}=0.16 \mathrm{~m} / \mathrm{s}$; (b) $\mathrm{v}=0.32 \mathrm{~m} / \mathrm{s} ;(\mathbf{c}) \mathrm{v}=0.48 \mathrm{~m} / \mathrm{s} ;(\mathbf{d}) \mathrm{v}=0.64 \mathrm{~m} / \mathrm{s}$. 
The disc volumetric wear VD was proportional to the correlation length Sal ( $\mathrm{R}$ was between 0.54 and 0.84 ). This dependence can be explained by the tendency to obtain the higher Sal parameter for the bigger surface height, determined by the Sk parameter. The remaining surface texture parameters: The rms slope Sdq and the peak density Spd were not strongly correlated with tribological parameters.

The volumetric wear levels were typically not correlated with parameters characterizing the friction force DSS, Fav, and F35. Only for the highest sliding speed $v=0.64 \mathrm{~m} / \mathrm{s}$ the average friction force Fav was proportional to wear levels of disc VD and balls VB; the coefficients of the linear correlation $\mathrm{R}$ amounted to 0.83 and 0.94 , respectively.

\section{Conclusions}

The results of the conducted research indicated many significant relationships between surface topography parameters and the tribological properties of tested samples.

Ssk and Sku parameters characterizing the shape of the surface ordinate distribution had significant impacts on the volumetric wear. A decrease in the value of the Ssk parameter and an increase in the value of Sku led to a reduction in the wear volume.

The wear volume of discs was also strongly correlated with the parameters characterizing the areal material ratio curve. It was shown that an increase in the value of the parameter Sk caused an increase in the volumetric wear level.

Wear of balls was proportional to wear of disc. An increase in the sliding speed resulted in a reduction in the coefficient of friction of the tribological system.

Author Contributions: Conceptualization: A.D., P.P., W.Z.; methodology: A.D., P.P., W.Z.; investigation and formal analysis: A.D., P.P., W.Z.; writing—original draft preparation: A.D., P.P., W.Z.; writing-review and editing: A.D., P.P., W.Z. All authors have read and agreed to the published version of the manuscript.

Funding: This research received no external funding.

Conflicts of Interest: The authors declare no conflict of interest.

\section{References}

1. Geometrical Product Specifications (GPS)—Surface texture: Areal_Part 2: Terms, Definitions and Surface Texture Parameters; ISO 25178-2:2012; International Standardization Organization: Geneva, Switzerland, 2012.

2. Svahn, F.; Kassaman-Rudolphi, A.; Wallen, E. The influence of surface roughness on friction and wear of machine element coatings. Wear 2003, 254, 1092-1098. [CrossRef]

3. Tayebi, N.; Polycarpou, A.A. Modeling the effect of skewness and kurtosis on the static friction coefficient of rough surfaces. Tribol. Int. 2004, 37, 491-505. [CrossRef]

4. Chang, W.R.; Hirvonen, M.; Gronqvist, R. The effects of cut-off length on surface roughness parameters and their correlation with transition friction. Safety Sci. 2004, 42, 755-769. [CrossRef]

5. Reizer, R.; Galda, L.; Dzierwa, A.; Pawlus, P. Simulation of textured surface topography during a low wear process. Tribol. Int. 2011, 44, 1309-1319. [CrossRef]

6. Grabon, W.; Pawlus, P.; Wos, S.; Koszela, W.; Wieczorowski, M. Effects of honed cylinder liner surface texture on tribological properties of piston ring-liner assembly in short time tests. Tribol. Int. 2017, 113, 137-148. [CrossRef]

7. Wang, S.; Hu, Y.-Z.; Tan, Q.-C. Frictional behaviour of engineering surfaces in overall lubrication regimes of point contacts. Proc. Inst. Mech. Eng. J J. Eng. 2011, 225, 1071-1080. [CrossRef]

8. Wang, S.; Hu, Y.-Z.; Wang, W.-Z.; Wang, H. Transition of frictional states and surface roughness affects in lubricated contacts. Proc. Inst. Mech. Eng. J J. Eng. 2008, 222, 407-414. [CrossRef]

9. Sedlacek, M.; Podgornik, B.; Vizintin, J. Correlation between standard roughness parameters skewness and kurtosis and tribological behaviour of contact surfaces. Tribol. Int. 2012, 48, 102-112. [CrossRef]

10. Sedlacek, M.; Podgornik, B.; Vizintin, J. Influence of surface preparation on roughness parameters, friction and wear. Wear 2009, 266, 482-487. [CrossRef]

11. Dzierwa, A. Influence of surface preparation on surface topography and tribological behaviours. Arch. Civ. Mech. Eng. 2017, 17, 502-510. [CrossRef] 
12. Grabon, W.; Pawlus, P.; Sep, J. Tribological characteristics of one-process and two-process cylinder liner honed surfaces under reciprocating sliding conditions. Tribol. Int. 2010, 43, 1882-1892. [CrossRef]

13. Kubiak, K.J.; Bigerelle, M.; Mathia, T.G.; d'Hardivilliers, W. Roughness of interface in dry contact under fretting conditions. In Proceedings of the 13th International Conference on Metrology and Properties of Engineering Surfaces, Twickenham Stadium, UK, 12-15 April 2011; pp. 99-102.

14. Kubiak, K.J.; Liskiewicz, T.E.; Mathia, T.G. Surface morphology in engineering applications: Influence of roughness on sliding and wear in dry fretting. Tribol. Int. 2011, 44, 1427-1432. [CrossRef]

15. Pawlus, P.; Michalczewski, R.; Dzierwa, A.; Lenart, A. The effect of random surface topography height on fretting in dry gross slip conditions. Proceedings of the Institution of Mechanical Engineers. Proc. Inst. Mech. Eng. J J. Eng. 2014, 228, 1374-1391. [CrossRef]

16. Lenart, A.; Pawlus, P.; Dzierwa, A.; Sep, J.; Dudek, K. The effect of surface topography on dry fretting in the gross slip regime. Arch. Civ. Mech. Eng. 2017, 17, 894-904. [CrossRef]

17. Nyman, P.; Maki, R.; Olsson, R.; Ganemi, B. Influence of surface topography on friction characteristics in wet clutch applications. Wear 2006, 261, 46-52. [CrossRef]

18. Menezes, P.L.; Kailas, S.V. Kishore Influence of roughness parameters on coefficient of friction under lubricated conditions. Sadhana 2008, 33, 181-190. [CrossRef]

19. Singh, R.; Melkote, S.N.; Hashimoto, F. Frictional response of precision finished surfaces in pure sliding. Wear 2005, 258, 1500-1509. [CrossRef]

20. Ma, Z.; Henein, N.A.; Bryzik, W.; Glidewell, J. Break-in liner wear and piston ring assembly friction in a spark-ignited engine. Tribol. Trans. 1998, 41, 497-504. [CrossRef]

21. Talysurf CCI 3D Non-Contact Surface Profiler System. User's Guide; K505/70-01 Issue 5.2; Taylor Hobson: Leicester, UK, 2005; pp. 1-154.

22. Dzierwa, A.; Pawlus, P.; Zelasko, W.; Reizer, R. The study of the tribological properties of one-process and two-process textures after vapour blasting and lapping using pin-on-disc tests. Key Eng. Mater. 2013, 527, 217-222. [CrossRef]

23. Sedlacek, M.; Gregorcic, P.; Podgornik, B. Use of the roughness parameters S sk and Sku to control friction-A method for designing surface texturing. Tribol. Trans. 2017, 60, 260-266. [CrossRef]

24. Gadelmawla, E.S.; Koura, M.M.; Maksoud, T.M.A.; Elewa, I.M.; Soliman, H.H. Roughness parameters. J. Mater. Process. Technol. 2002, 123, 133-145. [CrossRef]

25. Pawlus, P.; Wieczorowski, M.; Mathia, T.G. The Errors of Stylus Methods in Surface Topography Measurements; ZAPOL: Szczecin, Poland, 2014; pp. 1-267.

26. Johansson, S.; Nilsson, P.H.; Ohlsson, R.; Anderberg, C.; Rosen, B.G. New cylinder liner surfaces for low oil consumption. Tribol. Int. 2008, 41, 854-859. [CrossRef] 